\title{
Meta-analysis of incidence of early lung toxicity in 3-dimensional conformal irradiation of breast carcinomas
}

\author{
Kumar Gokula1, ${ }^{1,2 *}$, Arul Earnest ${ }^{4}$ and Lea Choung Wong ${ }^{2}$
}

\begin{abstract}
Background: This meta-analysis aims to ascertain the significance of early lung toxicity with 3-Dimensional (3D) conformal irradiation for breast carcinomas and identify the sub-groups of patients with increased risk.

Methods: Electronic databases, reference sections of major oncological textbooks and identified studies were searched for synonyms of breast radiotherapy and radiation pneumonitis (RP). Major studies in thoracic irradiation were reviewed to identify factors frequently associated with RP. Meta-analysis for RP incidence estimation and odds ratio calculation were carried out.

Results: The overall incidence of Clinical and Radiological RP is $14 \%$ and $42 \%$ respectively. Ten studies were identified. Dose-volume Histogram (DVH) related dosimetric factors (Volume of lung receiving certain dose, $V_{\text {dose }}$ and Mean lung Dose, MLD), supraclavicular fossa (SCF) irradiation and age are significantly associated with RP, but not sequential chemotherapy and concomitant use of Tamoxifen. A poorly powered study in IMN group contributed to the negative finding. Smoking has a trend towards protective effect against RP.
\end{abstract}

Conclusion: Use of other modalities may be considered when Ipsilateral lung $V_{20 G y}>30 \%$ or MLD $>15$ Gy. Extra caution is needed in SCF and IMN irradiation as they are likely to influence these dosimetric parameters.

Keywords: Breast radiotherapy, Radiation pneumonitis, Lung toxicity, Meta-analysis

\section{Introduction}

Postoperative radiotherapy (RT) after the breast conservative surgery $(\mathrm{BCT})$ or mastectomy, have been shown to reduce the rates of local recurrence and death in breast carcinomas (BC) [1-5]. It is the standard practice to offer patients adjuvant RT to whole breast or chest wall, with or without loco-regional RT (LRRT), depending on the stage of disease. The regional fields include the ipsilateral supraclavicular fossa (SCF). The Axilla (Ax) and internal mammary nodal region (IMN) RT is uncommon due to the toxicities associated with them [6-10].

Radiation pneumonitis (RP) and lung fibrosis are two known toxicities that arise from incidental irradiation of adjacent ipsilateral lung in BC. Other toxicities include

\footnotetext{
* Correspondence: gokudroid@gmail.com

'Advanced Medical and Dental Institute, Universiti Sains Malaysia, Penang, Malaysia

${ }^{2}$ Department of Radiation Oncology, National University Cancer Institute,

Singapore, Singapore

Full list of author information is available at the end of the article
}

breast fibrosis, cardiac toxicity, skin toxicity and lymphoedema of the ipsilateral upper limb. The risk of cardiac toxicity in tangential radiotherapy treatment of left breast or chest wall is well studied in literature [6-8]. However most studies were pre-conformal CT-based planning and IMN irradiation was a common practice then.

RP and lung fibrosis is believed to represent the different ends in the clinical course of the disease rather than separate entities altogether. The natural history of the radiation lung injury can be divided into 5 phases: immediate phase (hours to days); latent phase; acute exudative/clinical RP phase (4-12 weeks post-RT); intermediate phase with resolution of exudate and deposition of fibroblast and the final phase when fibrosis is established (usually $6-12$ months post-RT) [11-13]. Type II pneumocytes which produce surfactant are the cells associated with RP $[13,14]$.

Literature on RP in breast irradiation is very heterogeneous: different simulation techniques (conventional fluoroscopy-based versus CT-based), different treatment 
planning systems [2-Dimensional (2-D) versus highly conformal CT-based], different sites treated (chest wall/ breast +/- Ax/SCF/IMN) and also use of electrons to treat the chest wall +/- IMN after mastectomy.

McDonald et al. [11] reported in 1995, the incidence of radiological and clinical RP to be in the range of $27-$ $40 \%$ and $0-10 \%$ respectively in patients with BC undergoing radiotherapy based on 2 studies in 1980. The details of the radiotherapy techniques and the grades of both radiological and clinical RP were not mentioned in that review. These figures are the most likely estimates of RP incidence in non-conformal planning days.

Currently there is a trend towards minimizing toxicity to organs at risks in the adjuvant treatment of breast cancer. The newer RT modalities or techniques used include Intensity Modulated Radiotherapy (IMRT), Tomotherapy, Accelerated Partial Breast Irradiation (APBI) and Intraoperative Radiotherapy (IORT). IMRT and Tomotherapy produce more conformal radiation delivery at the expense of increased integral dose. These newer modalities are more expensive and needs longer planning time. Smith $\mathrm{BD}$ et al. [15] has recently shown that the adoption of IMRT for BC in the United States have increased the cost of breast irradiation significantly.

In centers where there are limited resources or financial constraints, it is important to allocate the available resources accordingly without compromising the breast cancer patient's treatment outcome. Hence the important questions are:

1. Which patient subgroups will benefit from these newer modalities of treatment in regards to early lung toxicity?

2. What are the dosimetric parameters, treatment factors and patient factors which predict for RP or early lung toxicity in adjuvant 3-Dimensional Conformal RT (3D-CRT) for BC?

\section{Methodology}

Electronic databases were searched from 1995 till April 2011 (3D-CRT techniques would have been very unlikely before 1995) using the following inclusion and exclusion criteria for adjuvant $\mathrm{RT}$ studies in $\mathrm{BC}$ :

\section{Inclusion Criteria:}

The use of 3D-CRT.

Tangential photon fields or electrons for breast/chest wall treatment +/- LRRT.

Histology proven BC or Ductal/Lobular Carcinomain-situ (DCIS/LCIS).

Stage I-III BC.

Female.

Mastectomy or BCT.
Total dose of 50-60 Gy (or its equivalence in different dose fractionation).

Exclusion Criteria:

Male.

Non-3D-CRT techniques.

Stage IV BC.

Concurrent chemotherapy.

The use of Tomotherapy, APBI, interstitial implants, IORT or IMRT.

Inoperable BC.

Search was performed using PubMed search builder for Breast Radiotherapy AND Meta-analysis (or Systematic review); Breast Radiotherapy AND Toxicity; Breast AND Radiotherapy AND Pneumonitis. This produced 536 hits. Cochrane library, Google Scholar and reference sections of the major Radiation Oncology textbooks were searched to ensure no important studies were missed. Eight studies from these results were initially identified for the analysis and two further studies were identified by searching the reference sections of those 8 studies. Although four of the identified studies had overlapping data, different endpoints were used in the analysis [16-19]. Only one retrospective study was included [20].

Factors affecting the incidence and severity of RP were identified from the above studies and other thoracic irradiation studies (lung, oesophagus, lymphoma and others), which reported on RP. These were dosimetric parameters $\left(\mathrm{V}_{\text {dose }}\right.$ and $\mathrm{MLD}$ ), patient factors (smoking and age) and treatment factors (SCF and IMN RT; concomitant Tamoxifen and sequential chemotherapy).

Radiological RP grading criteria used include Arrigada, modified lung fibrosis CTC (common toxicity criteria) and Nishioka system [21]. The grouping of low grade radiological RP in this analysis are: Modified Arrigada grade 1 in Holli's study [19] and Arrigada scores 1-3 in Goldman's study [22]. Any grades or scores above these values are grouped as high grade radiological RP. The clinical RP is also divided into low and high grades with clinical RP grade 1 classified as low grade and clinical $\mathrm{RP}$ grade 2 or more grouped as high grade.

\section{Statistical methods}

Data was analysed using Stata ${ }^{\circ}$ software, version 11.0 (Stata Corp College Station, TX, USA), and level of significance set at 5\%. To estimate the incidences of clinical RP and radiological RP, we pooled the values from each study, using the random effects meta-analysis model. As for the association between treatment-related factors and RP, we combined the individual effect sizes (Odds Ratios) using the random-effects model, using the method of DerSimonian and Laird, with the estimate of 
heterogeneity being taken from the inverse-variance fixed-effect model. Heterogeneity between studies was assessed by the chi-square test for heterogeneity as well as examining the $\mathrm{i}$-squared statistic, which quantifies the level of heterogeneity. In the event of heterogeneity, we used the random effect model instead of the fixedeffect model to analyse the data. Publication bias for the primary endpoint (incidence of RP) was assessed via the Egger's test.

\section{Results}

Incidence of RP

\section{Radiological RP}

The overall incidence of radiological RP in our metaanalysis [Figure 1] is $42 \%(95 \% \mathrm{CI}=22-62 \%)$ with large heterogeneity in the included studies (I-squared $=97.4 \%$, $\mathrm{p}<0.001)$ and Egger's test did not show significant publication bias $(\mathrm{p}=0.151)$. In the study by Marco Krengli et al. [23], the high detection rate of RP (85\%) could be attributed to the use of high resolution CT images for post radiotherapy lung assessment. The incidence of RP was low, as reported by Akiko Kubo et al. [24] because only tangential RT fields were used and the RP assessment was mainly done by Chest X-ray (CXR).

The overall incidence of low grade and high grade radiological $\mathrm{RP}$ are $22 \%(95 \% \mathrm{CI}=17-27 \%)$ and $12 \%(95 \% \mathrm{CI}=$ 9-33\%) respectively. The I-squared heterogeneity index for low grade radiological RP is $1.7 \%(\mathrm{p}=0.313)$ and $97.5 \%(\mathrm{p}<0.001)$ for high grade.

\section{Clinical radiation pneumonitis}

The overall incidence of clinical RP [Figure 2] is 14\% (95\% CI $=8-21 \%$ ) with large heterogeneity in the included studies (I-squared $=89.7 \%, \mathrm{p}<0.001$ ). The Egger's test did not show significant publication bias $(p=0.376)$.
Either CTC2.0 or CTC3.0 assessment was used in the studies. There are no reported cases of CTC grade 4 or 5 toxicity in any of the studies.

The overall incidence of low grade and high grade clinical $\mathrm{RP}$ is $14 \%(95 \% \mathrm{CI}=9-18 \%)$ and $4 \%(95 \% \mathrm{CI}=2-7 \%)$ respectively. There is also large heterogeneity in the studies with I-squared $=79.3 \%(\mathrm{p}=0.002)$ and I-squared $=82.4 \%$ $(\mathrm{p}=0.001)$ for low and high grade clinical RP respectively. The Egger's test for publication bias is not significant for either low or high grade clinical RP $(\mathrm{p}=0.855$ and 0.407).

\section{DVH-related parameters}

\section{Volume of lung receiving a specified dose $\left[V_{\text {dose }}\right]$}

A systematic review by George Rodrigues et al. [25] in 2004 analysed 5 trials and reported a strong correlation between $V_{\text {dose }}$ and RP in lung tumour irradiations. In contast, $\mathrm{V}_{\text {dose }}$ of the lung in breast or chest wall irradiation is likely to be smaller in value and hence we limit our analysis to studies reporting on $\mathrm{V}_{20 \mathrm{~Gy}}$ to $\mathrm{V}_{25 \mathrm{~Gy}}$ [Table 1] though some studies do report on other $V_{\text {dose }}$ values.

Berit Wennberg et al. [16] analyzed 121 patients who had node-positive stage II BC, which was a subgroup from the main study by Perh Lind et al. [17]. He presented the data in the form of mean cumulative ipsilateral lung DVHs for four different treatment techniques. Data extracted from this paper showed that treatments techniques with $\mathrm{V}_{20 \mathrm{~Gy}} \leq 20 \%$ had a lower incidence of RP compared to $\mathrm{V}_{20 \mathrm{~Gy}}>20 \%$ ( $12.5 \%$ vs $28.4 \%$ respectively). Perh Lind et al. [26] also looked at a subgroup of 128 patients from his earlier paper [17]. He analyzed the data using the ROC (receiver operating characteristics curves), which showed the significance of ipsilateral $\mathrm{V}_{20 \mathrm{~Gy}}$ in clinical RP $(p=0.008)$ and radiological RP $(p=0.009)$.

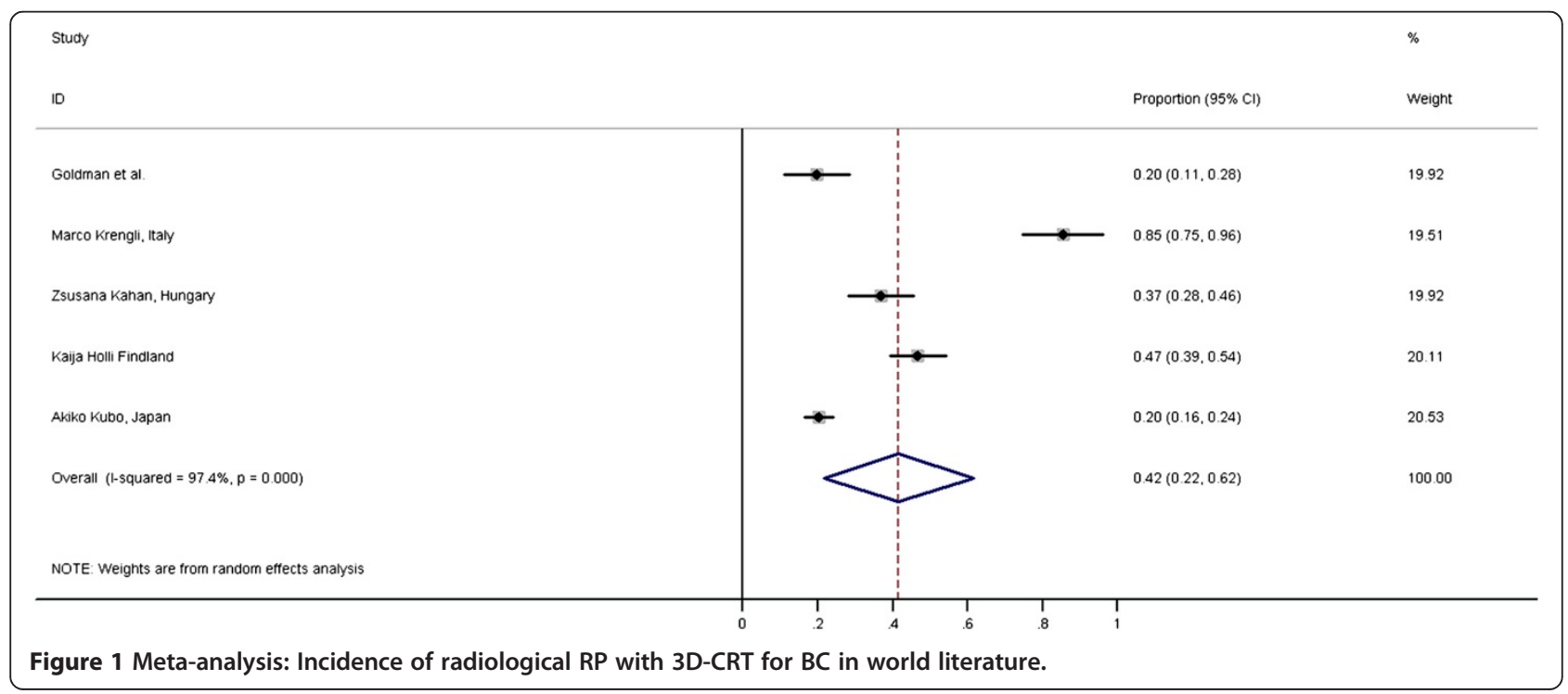




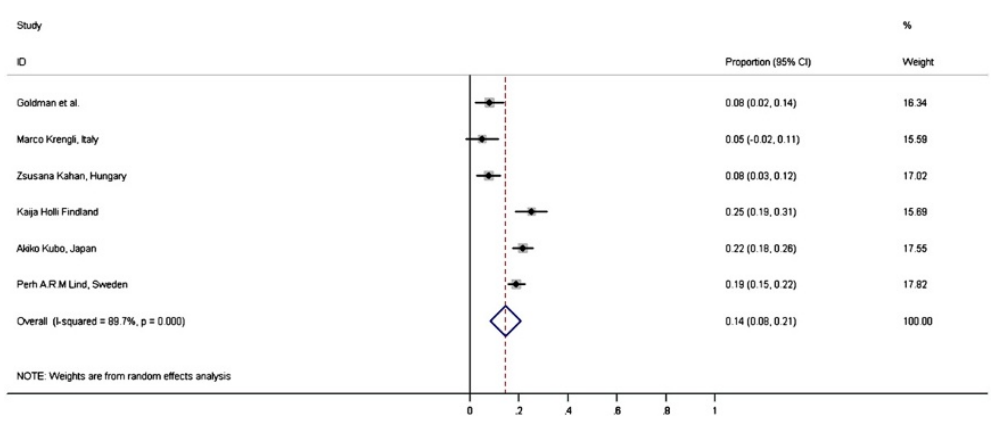

Figure 2 Meta-analysis: Incidence of clinical RP with 3D-CRT for BC in world literature.

\section{Mean lung dose (MLD)}

MLD is also significantly correlated with the incidence and grade of RP, mostly in studies involving lung cancer or other thoracic irradiations [27-30]. However the data on MLD in BC is very limited [Table 2].

Though these studies used different end points, all of them showed significant impact of MLD on lung toxicity. As with the $\mathrm{V}_{\text {dose }}$, the study by Perh Lind et al. showed significant correlation between increasing MLD and the grade of lung toxicity using gamma statistics $(\mathrm{p}<0.001)$ [17]. The MLD was 7.5 Gy, 13.5 Gy and 16.0-16.6 Gy for no RP, mild RP and moderate RP respectively.

In Zsusana Kahan's study $20.5 \%$ of patients with radiological RP developed clinical symptoms. The MLD of patients with no RP versus RP in this study was 12.2 Gy vs 15.0 Gy respectively [31].

\section{Treatment factors}

\section{SCF irradiation}

Current meta-analysis shows a significant effect of SCF irradiation on the incidence of RP [Figure 3]. The odds ratio (OR) of having RP in this group is 5.07 (95\% CI = 1.95-13.22). The heterogeneity between the studies (I-squared) is $70.1 \%(\mathrm{p}=0.035)$.

The subgroup analysis of 121 patients with node positive stage II $\mathrm{BC}$ by Berit Wennberg et al. also showed significant effect of SCF irradiation on RP [16].

\section{IMN chain irradiation}

Figure 4 shows that OR of having RP with IMN irradiation is $1.04(95 \% \mathrm{CI}=0.43-2.54)$ and there is no statistically significant heterogeneity between the studies (I-squared = $66.3 \%, \mathrm{p}=0.052$ ). The study by Goldman et al. had only 9 patients in the no IMN RT group [22]. The fields used in the IMN irradiation in the studies above vary significantly and they included oblique electron beam, anterior photon beam or deep oblique field.

\section{Concomitant tamoxifen}

The evidence of Tamoxifen causing lung fibrosis is so far unclear $[32,33]$. The OR of having RP with concomitant
Tamoxifen use is 1.20 (95\% CI $0.57-2.51)$ and heterogeneity index (I-squared) is $69.1 \%(\mathrm{p}=0.039)$.

\section{Sequential chemotherapy-RT}

Data on sequential chemotherapy and RP in breast irradiation is very scarce in the literature. Most studies looked at individual chemotherapeutic agents especially the taxane group [34,35]. The analysed studies are heterogeneous with multiple agents used, different doses and intensity of the chemotherapy. For example, Lind et al. (Sweden) [17] reported the use of CMF, FEC, dose intensified FEC and high dose chemotherapy with stem cell rescue. Kubo et al. [24] and Lind et al. (Duke's) [20] did not mention the type of chemotherapy in their studies.

The OR of having RP in this group is $1.40(95 \% \mathrm{CI}=$ $0.44-4.50)$ with I-squared $=88.5 \%(\mathrm{p}<0.001)$ for heterogeneity of the included studies.

\section{Patient factors \\ Smoking}

The effect of smoking on RP has been studied in a few trials involving thoracic irradiation. In two lung cancer studies [36,37], smoking has been associated with lower incidence of lung toxicity.

This positive effect of smoking is also seen in a trial by Leif Bjermer et al. [38] which looked at inflammatory response in breast cancer patients by bronchoalveolar lavage. Another large retrospective review by Silvia Johansson et al. [39] looked at 405 women who underwent radiotherapy for breast or oesophageal cancers also showed similar findings.

Our analysis [see Figure 5] shows the OR of having RP in this smoking-group is $0.59(95 \% \mathrm{CI}=0.26-1.34)$ with heterogeneity index (I-squared) of 70.1\% $(\mathrm{p}=0.035)$.

\section{Age}

Lung irradiation studies showed conflicting results of age in predicting for RP [28,36,40-42]. See BC studies in Table 3. 
Table 1 Relationship between dose volume parameters and early lung toxicity in 3D-CRT for BC in world literature

\begin{tabular}{|c|c|c|c|c|c|c|c|}
\hline Author, Year of data collection & Country & $n$ & RP endpoint & Prognostic groups & Test type & $p$ value & Comments \\
\hline Perh Lind et al. 1994-1998 [17] & Sweden & 475 & Clinical RP CTC-NCIC & $\begin{array}{l}\text { Ipsilateral } V_{20 G y:} \approx 7 \%, \approx 20 \% \text {, } \\
\approx 30 \%, \approx 35 \%\end{array}$ & $\begin{array}{l}2 \text { sided Gamma statistics, } \\
\mathrm{G}=0.638\end{array}$ & $<0.001$ & $\begin{array}{l}\text { Correlation between increasing } V_{20 G y} \\
\text { to grade of lung toxicity. Assessed at } \\
1,4 \text { and } 7 \text { months. }\end{array}$ \\
\hline Zsusana Kahan et al. 2001-2004 [31] & Hungary & 119 & Radiological RP - CTC 2.0 & $\begin{array}{l}\text { Mean Ipsilateral } V_{20 G y}(\%) \\
(\mathrm{RP}-\text { vs RP+) }\end{array}$ & $\begin{array}{l}\text { Student's t-test ( } 24.8 \% \text { vs } \\
31.1 \%)\end{array}$ & 0.005 & 3 and 12 months post RT CT-Thorax. \\
\hline Javier Jaen et al. 2002 [44] & Spain & 39 & Change in perfused volume(\%) & Bilateral $V_{20 G y}$ & Corr. Coefficient $r=-0.414$ & 0.026 & 6,12 and 36 months lung perfusion test. \\
\hline \multirow[t]{2}{*}{ Marco Krengli et al. 2002 - 2003 [23] } & \multirow[t]{2}{*}{ Italy } & \multirow[t]{2}{*}{41} & \multirow[t]{2}{*}{ Radiological RP (G0-3) } & \multirow[t]{2}{*}{ Ipsi $V_{25 G y}$} & \multirow[t]{2}{*}{ ANOVA } & $0.0007(G 2$ vs G0) & \multirow[t]{2}{*}{3 and 9 months post RT CT-Thorax. } \\
\hline & & & & & & 0.02 (G3 vs G0) & \\
\hline Ulla Goldman et al. 2003 - 2005 [22] & Sweden & 40 & Radiological RP - Arigada score & $\begin{array}{l}\text { Mean Ipsilateral V } 206 y \text { (\%) } \\
\text { (RP- vs RP+) }\end{array}$ & $24 \%$ vs $30 \%$ & - & $\begin{array}{l}4 \text { months (CT-Thorax) and } 5 \text { months } \\
\text { (CXR). }\end{array}$ \\
\hline Akiko Kubo et al. 2005 - 2007 [24] & Japan & 413 & Radiological RP - CTC/AE 3.0 & $\begin{array}{l}\text { Ipsi } V_{20 G y} \leq 9.7 \%, \text { Ipsi } \\
V_{20 G y} \geq 9.8 \%\end{array}$ & Cox regression $R R=0.67$ & 0.13 (NS) & $\begin{array}{l}3 \text { monthly CXR for } 1 \text { year. Only tangential } \\
\text { whole breast irradiation. }\end{array}$ \\
\hline
\end{tabular}


Table 2 Relationship between MLD and early lung toxicity in 3D-CRT for BC in world literature

\begin{tabular}{llllll}
\hline Author, Year of data collection & Country & $\mathbf{n}$ & RP endpoint & Test type, & p value \\
\hline Perh Lind et al. 1994-1998 [17] & Sweden & 475 & Clinical RP CTC-NCIC & Gamma statistics G =0.669 & $<0.001$ \\
Zsusana Kahan et al. 2001-2004 [31] & Hungary & 119 & Radiological RP - CTC 2.0 & Student's t-test (RP + vs RP-) & 0.003 \\
Javier Jaen et al. 2002 [44] & Spain & 39 & Change in perfused volume (\%) & Correlation coefficient, $r=-0.447$ & 0.013 \\
\hline
\end{tabular}

$R P$ radiation pneumonitis, $n$ number of patients, CTC/CTC-NCIC common toxicity criteria, $R T$ radiotherapy, MLD mean lung dose.

\section{Discussion}

The early radiation induced pulmonary toxicity has been well studied in other thoracic irradiation, mostly involving lung cancers. Caution is needed in extrapolating the data in lung tumors to breast cancer patients. The demographics of the patients may differ significantly as can be seen in the proportion of smokers, age group, effect of the tumor itself on the lung function and also the location of the lung that is irradiated. Furthermore, the lung in $\mathrm{BC}$ patients is a healthy organ in contrast to lung cancer patients.

The major limitation that the authors faced in completing current analysis is the heterogeneity of the data in world literature, such as the clinical endpoints measurement, radiological and clinical RP grading system, different sensitivity in the detection tests of the radiological RP and the poor reporting of confounding factors in some studies.

Besides the dosimetric, treatment and patient factors mentioned earlier, other reported factors are pre-irradiation lung function and performance status, pre-existing respiratory diseases (chronic obstructive airway disease, interstitial pneumonitis, etc) and genetic predisposition. There is very little or no data on contribution of this factors in 3D-CRT for BC towards early lung toxicity and hence no analysis can be done.

\section{Radiological and clinical RP}

The previous review by Mc Donald et al. [11] in 1995 have reported incidence of radiological RP in range of $27-40 \%$ and clinical RP in to be in the range of $0-10 \%$. The overall incidence of radiological RP in current metaanalysis is $42 \%$ ( $95 \% \mathrm{CI}=22-62 \%$ ) which is marginally higher compared to the previous review by Mc Donald et al. This may be due to the use of more CT scans in current studies.

Clinical relevance low grade or high grade radiological $\mathrm{RP}$ leading to late lung toxicity is not well known currently and is an area for further research not only in breast cancer patients but also other thoracic irradiations. Five studies in current analysis have shown poor correlation between radiological RP and clinical RP $[18,19,22,31,43]$.

Fourteen per cent incidence of clinical RP in current analysis $(95 \% \mathrm{CI}=8-21 \%)$, is also higher than the previous estimate by McDonald. This can be due to more vigilant assessment by the physicians in current clinical trial settings. Furthermore, McDonald and colleagues only reported approximate values and the precise information was not always reported in the quoted studies. The late sequelae of low or high grade clinical RP is also not well known currently, as with radiological RP.

A subgroup analysis of 121 patients with stage II, node positive breast cancers by Berit Wennberg et al. [16]

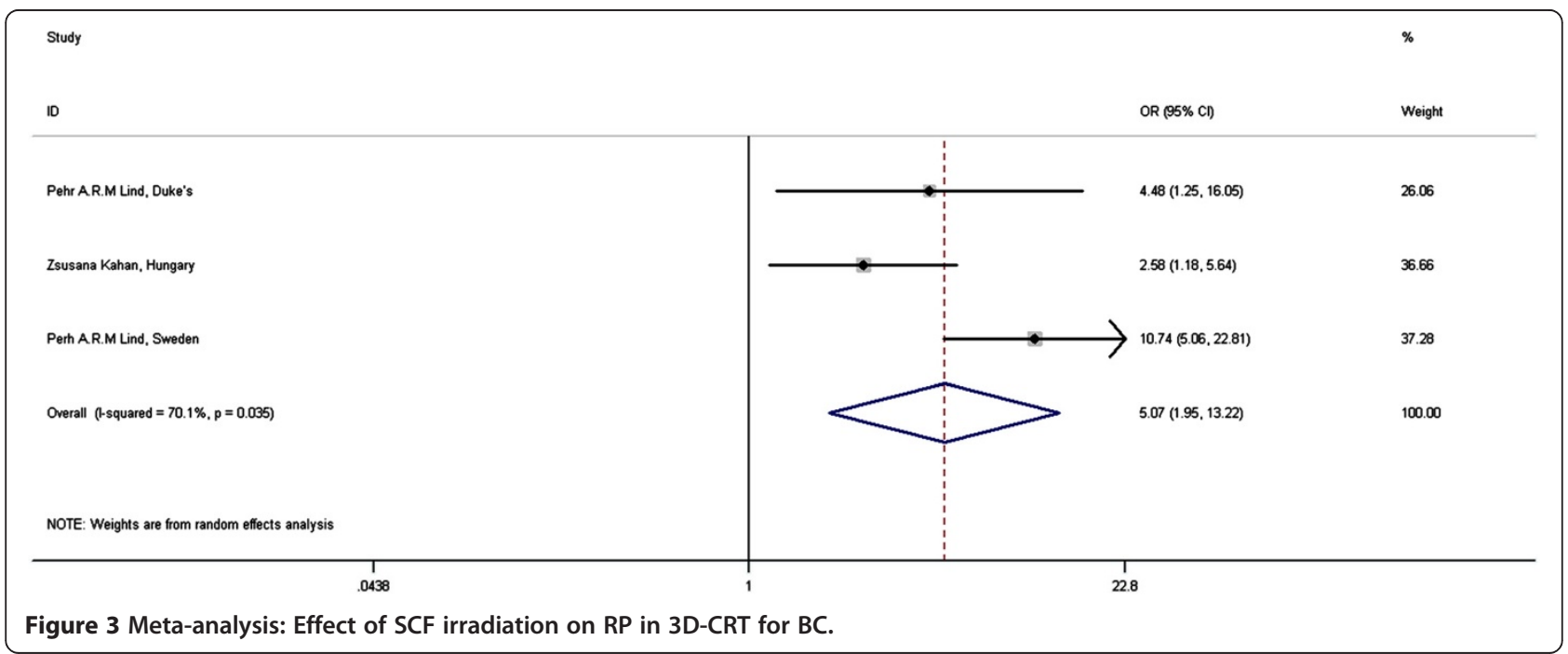




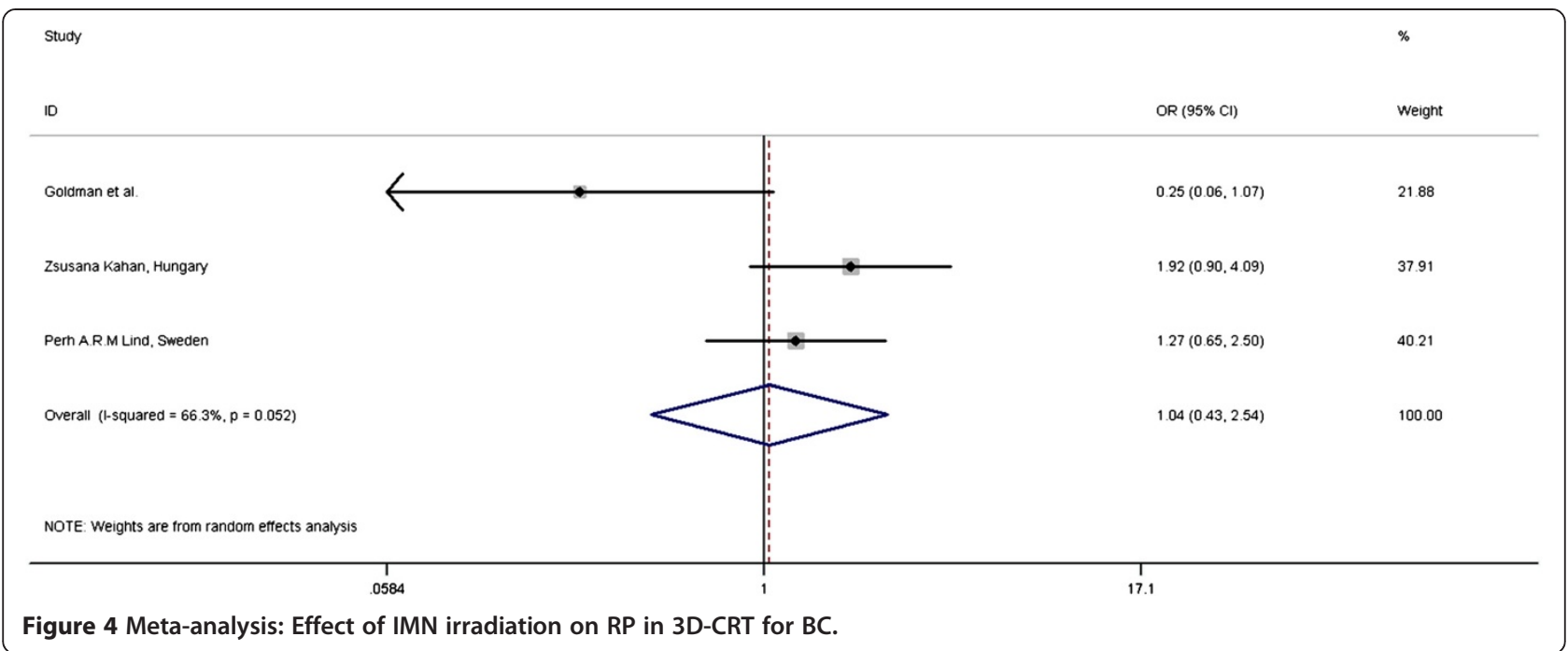

(from the large group of 475 patients in the study by Perh Lind et al. [17]) showed a slightly higher incidence of $23.1 \%$ clinical RP compared to $18.9 \%$ in the main study. This is probably due to the fact that the 475 patients recruited into the main study may include the mixture of very early stage disease who may not have had regional RT.

The reported incidences of clinical and radiological RP vary significantly between studies as seen in the test for heterogeneity (I-squared). This can be attributed to the different techniques, fields used and measurement variations of RP. Though the assessment of clinical RP is quite standardized using either CTC2.0 or CTC3.0 toxicity criteria, the threshold to diagnose clinical RP may vary significantly between physicians and between centers.

\section{DVH related dosimetric factors}

The DVH related parameters $\left(\mathrm{V}_{\text {dose }}\right.$ and MLD) are strongly associated with the clinical RP, radiological RP and change in physiologic lung functioning in the current analysis. The study by Akiko Kubo et al. [24] was insignificant most likely because of low ipsilateral $\mathrm{V}_{20 \mathrm{~Gy}}$ of $9.6 \%$ (mean) and $18.8 \%$ (maximum).

In another study, Javier Jaen et al. [44] had shown that bilateral $V_{20}$ was closely correlated to the change in perfused volume. However it is beyond the scope of this paper to discuss the merits of physiological or functional lung damage assessment.

It is difficult to deduce the exact threshold value of $\mathrm{V}_{20 \mathrm{~Gy}}$ for clinical practice from this meta-analysis. However, other RT techniques or modalities can be considered, when ipsilateral $V_{20 G y}>30 \%[17,22,31]$. Some clinical

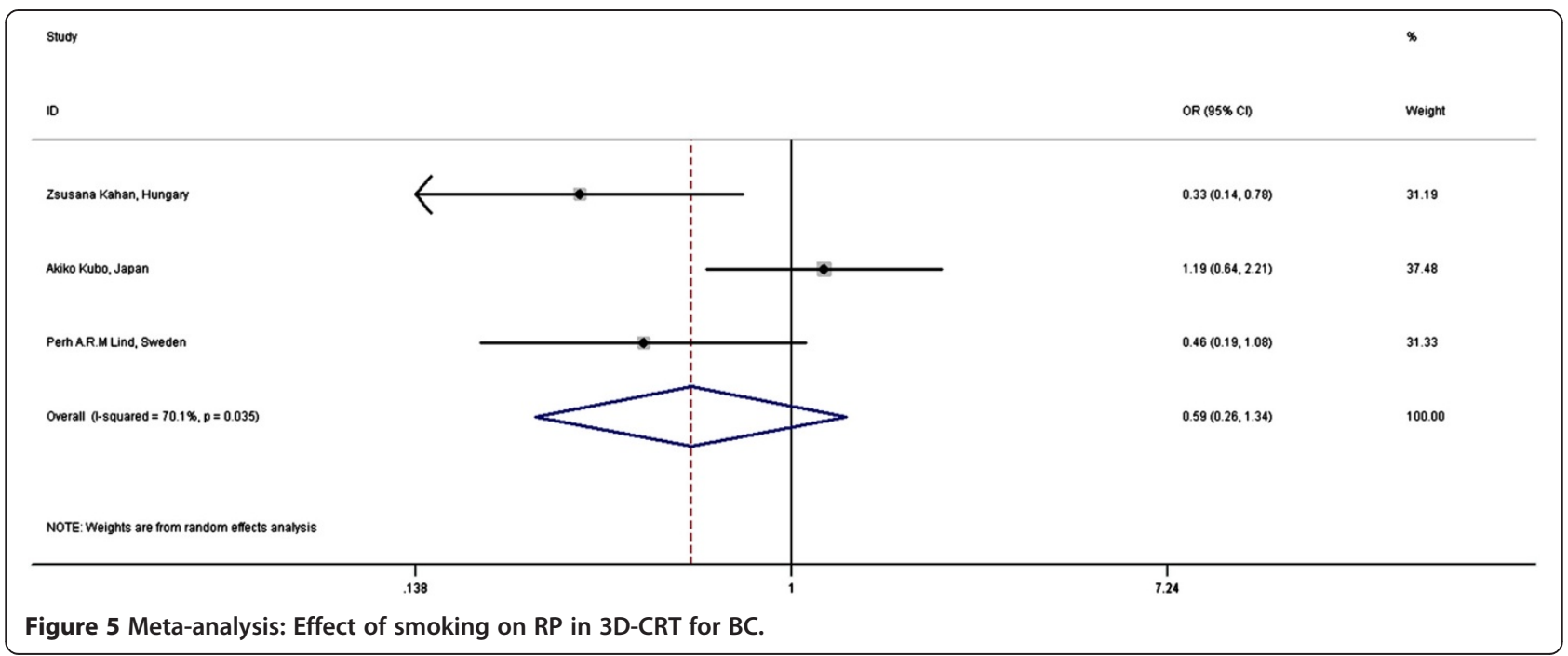


Table 3 Relationship between age and radiation pneumonitis in 3D-CRT for BC in world literature

\begin{tabular}{|c|c|c|c|c|c|c|c|}
\hline Author, Year ${ }^{*}$ & Country & $\mathrm{n}$ & RP endpoint & Prognostic groups & Test type (results) & $p$ value & Comments \\
\hline \multirow[t]{2}{*}{ Lind et al. 1994-1998 [20] } & Duke's & 613 & Clinical RP, Grade $>2$ & Median age & Mann-Whitney test & 0.64 & RP > Grade 2 only (retrospective) \\
\hline & & & & (RP- vs RP+) & (54.9 yrs vs 55.2 yrs) & & \\
\hline \multirow[t]{2}{*}{ Lind et al. 1994-1998 [17] } & Sweden & 180 & Clinical RP CTC-NCIC & Mean age & Students t-test & $<0.001$ & Loco-regional RT after mastectomy \\
\hline & & & & $(\mathrm{RP}-\mathrm{vs} \mathrm{RP}+)$ & (55.4 yrs vs 62.6 yrs) & & \\
\hline \multirow[t]{2}{*}{ Kahan et al. 2001 - 2004 [31] } & Hungary & 119 & Radiological RP - CTC 2.0 & Mean age & Student's t-test & 0.012 & - \\
\hline & & & & $(\mathrm{RP}-\mathrm{vs} \mathrm{RP}+)$ & (56.2 yrs vs 61.5 yrs) & & \\
\hline Jaen et al. 2002 [44] & Spain & 39 & Perfused lung volume (\%) & $\leq 55 \mathrm{yrs},>55 \mathrm{yrs}$ & Box plot: $\leq 55$ yrs vs $>55$ yrs & NS & Reduced perfusion in older age group \\
\hline \multirow[t]{2}{*}{ Kubo et al. $2005-2007$ [24] } & Japan & 413 & Radiological RP - CTC/AE 3.0 & $\leq 50 \mathrm{yrs},>50 \mathrm{yrs}$ & Cox regression model & 0.20 & Only tangential whole breast irradiation \\
\hline & & & & & $(\mathrm{RR}=0.76,95 \% \mathrm{Cl} 0.49-1.2)$ & & \\
\hline
\end{tabular}

$R P$ radiation pneumonitis, $n$ number of patients, $C$ confidence interval, CTC/CTC-NCIC common toxicity criteria, $R T$ radiotherapy, ${ }^{*}$ year of data collection, $N S$ statistically not significant. 
scenarios with high $\mathrm{V}_{20 \mathrm{~Gy}}$ are very curved chest wall, bilateral breast radiotherapy and locally advanced BC. The ipsilateral $V_{20 G y}$ should be kept below $24 \%$ if possible without compromising the required RT field coverage. The study by Akiko Kubo et al. [24] implies that further attempts at reducing ipsilateral $\mathrm{V}_{20 \mathrm{~Gy}}$ below $20 \%$ may not be of any benefit.

There are other models in radiation induced lung injury that are not analyzed in this paper such as the normal tissue complication probability (NTCP) model and more advanced biologically based models $[25,45,46]$. There is very limited data on the use of these models in $\mathrm{BC}$.

The large study of lung cancer patients by Kwa et al. [27] addressing RP have recommended the use of MLD or NTCP to predict the risk of RP. MLD is also found to be highly correlated to $\mathrm{V}_{20 \mathrm{~Gy}}$ in lung irradiation studies $[27,29]$. The three studies quoted in this current analysis do show a strong relationship between MLD and early lung toxicity. Based on the studies by Perh Lind et al. [17] and Zsusana Kahan et al. [31], it should be safe if the MLD is limited below the range of 12-15 Gy to avoid serious lung toxicity in 3D-CRT irradiation for BC. Other techniques or modalities of radiotherapy may be considered if MLD exceeds 15 Gy.

\section{Treatment factors}

SCF irradiation shows a strong association with RP incidence $(\mathrm{OR}=5.07)$. The addition of SCF irradiation increases the amount of lung tissue irradiated and hence MLD and $V_{\text {dose }}[47,48]$.

The reported incidence of IMN and medial SCF LN metastasis is between 4-9\% in axillary node negative patients and $16-52 \%$ in axillary node positive patients [49-52]. Despite the reported toxicities, positive outcomes from 2 studies by Overgaard $\mathrm{M}$ et al. $[2,3]$ have renewed the interest in IMN irradiation as part of LRRT. Furthermore, modern conformal techniques are likely to reduce the heart dose. The current view of IMN irradiation may change depending on the outcome of EORTC trial 22922/10925 which completed accrual in 2004 and results are expected in 2012 [49]. The three years toxicity profile update of 4004 patients with IMNmedial SCF field irradiation reported a $4.3 \%$ lung toxicity rate in the IMN arm versus $1.3 \%$ in no IMN arm $(p<0.0001)$. There were no statistically significant difference between the two groups with regards to cardiac toxicity. Poorly powered study by Goldman et al. (9 patients in no-IMN RT group) [22] caused the nonsignificant findings in current meta-analysis.

Concomitant use of Tamoxifen has no statistically significant effect on RP in this meta-analysis, as in earlier studies [32,33]. Three large retrospective studies [53-55] examined the concomitant and sequential Tamoxifen in
BC patients, and concluded that the use of both concomitant and sequential Tamoxifen was acceptable in terms of local relapse, distant metastasis and secondary malignancies. There was no statistically significant difference in lung toxicity between the groups.

The influence of concurrent chemotherapy-RT on RP incidence has been well studied in thoracic irradiation $[11,28,56]$ and also two BC studies [11,57]. Concurrent chemotherapy-RT is not analyzed in current paper as it is seldom practised nowadays.

Data on sequential chemotherapy and RP in breast irradiation is very scarce in the literature [34,35]. Our result is not significant probably because of heterogeneous studies. Adjuvant Taxanes and Cyclophosphamide or biological agents (Bevacizumab) [58] have been reported to increase the risk of RP. Anthracyclines and Taxanes [59] are potent radiosensitizers. Cyclophosphamide have been reported to cause lung injury with or without the addition of RT in some case series [60]. Radiation recall can occur if Paclitaxel is used after RT and can cause pathological changes in the lungs at the previous RT field. Hence readers are encouraged to refer to data on individual drugs in the literature for clinical practice.

\section{Patient factors}

There is a trend towards protective effect for smokers in breast irradiation in our meta-analysis. This effect was also reported in two other studies of thoracic irradiation $[36,37]$. This finding is quite puzzling because we expect that smokers with already damaged lung would be more susceptible to radiation induced lung injury. Some possible explanations are: 1) smokers may have higher threshold to develop clinical symptoms due to their already damaged epithelium; 2) the local immune reaction may not be as strong as non-smokers due to the damage to immune cells such as tissue macrophages in the lung epithelium causing reduced antibody secretion and exudates; 3$)$ tissue hypoxia in smokers may have radio protective effect; 4) lung scarring in smokers may mask the appearance of RP on CT scans.

In current analysis, there is a conflicting effect of age on both radiological and clinical RP in 3D-CRT for BC. The studies by Akiko Kubo et al. [24] and Perh Lind et al. (Duke's) [20] did not show statistically significant effect of age. In the former study, only tangential whole breast irradiation was used and the volume of irradiated lung was very small. There could have been significant bias in retrospective data in the latter study.

Based on the other three studies, age $>55$ yrs is a risk factor for RP in 3D-CRT for BC. However, the long term effect of early lung toxicity is not known and may take many years before it becomes clinically significant, especially in the younger age group. 
Another type of early lung toxicity reported in the literature but not discussed here is the radiationinduced bronchiolitis obliterans organizing pneumonia (BOOP) syndrome in which the lung injury occurs outside the radiation field or even in the contra-lateral lung. Kubo et al. have reported 2.9\% incidence of BOOP syndrome with all cases of radiological $\mathrm{RP} \geq$ grade 2 developing BOOP syndrome. A survey in major hospitals in Japan from August 1999 to March 2000 showed an incidence of 1.8-2.19\% in patients radiated after BCT [24,61].

\section{Conclusion}

The DVH-related parameters ( $\mathrm{V}_{\text {dose }}$ and MLD) and SCF irradiation are the strongest parameters associated with RP. Attempt should be made where possible to keep the ipsilateral lung $\mathrm{V}_{20 \mathrm{~Gy}}<24 \%$ and MLD $<15$ Gy without compromising the required radiotherapy coverage. Other RT techniques can be considered when ipsilateral lung $\mathrm{V}_{\text {20Gy }}>30 \mathrm{~Gy}$ or MLD $>15 \mathrm{~Gy}$. Other factors that increase the risk of RP are age $>55$ yrs and probably IMN irradiation. However, caution is needed in treating younger age group due to the possibilities of late sequealae.

Concomitant Tamoxifen do not increase the risk of developing RP. Readers are encouraged to search the data on individual chemotherapeutic agents for clinical practice. Though smoking is noted to have protective effect, this can just be a masking effect rather than physiological protection against radiation induced damage.

Biochemical markers can be another factor to predict for early lung toxicity in 3D-CRT for BC. The combination of elevated transforming growth factor (TGF)-beta1 levels during RT and MLD has been reported as having predictive value in non-small cell lung cancers [62]. This together with use of radioprotectors such as Pentoxifylline can be an area for further research in RP [63].

\section{Consent}

No individual patient consent was required for the publication of this manuscript as it only involves analysis of published trials.

\section{Competing interests}

The authors declare no conflict of interest. The authors alone are responsible for the content and writing of the paper.

\section{Authors' contributions \\ All authors' contributed equally for the work in this manuscript. GK and WLC was involved in the initial proposal writing and was later joined by EA in the database search process. Thereafter, extracting the raw data from the publications were done by GK and WLC. EA involved mostly in the statistical analysis for the manuscript. All three authors actively participated in the final write-up and also iterative correction of this manuscript. All authors read and approved the final manuscript.}

\section{Author details}

${ }^{1}$ Advanced Medical and Dental Institute, Universiti Sains Malaysia, Penang, Malaysia. ${ }^{2}$ Department of Radiation Oncology, National University Cancer Institute, Singapore, Singapore. ${ }^{3}$ William Buckland Radiotherapy Centre,
Alfred Health, Melbourne, Australia. ${ }^{4}$ Centre for Quantitative Medicine, Office of Clinical Sciences, Duke-NUS Graduate Medical School, Singapore,

Singapore.

Received: 25 April 2013 Accepted: 19 September 2013

Published: 14 November 2013

\section{References}

1. Clarke M, Collins R, Darby S, Davies C, Elphinstone P, Evans E, Godwin J, Gray R, Hicks C, James S, MacKinnon E, McGale P, McHugh T, Peto R, Taylor C, Wang Y, Early Breast Cancer Trialists' Collaborative Group (EBCTCG): Effects of radiotherapy and of differences in the extent of surgery for early breast cancer on local recurrence and 15-year survival: an overview of the randomised trials. Lancet 2005, 366:2087-2106.

2. Overgaard M, Hansen PS, Overgaard J, Rose C, Andersson M, Bach F, Kjaer M, Gadeberg CC, Mouridsen HT, Jensen MB, Zedeler K: Postoperative radiotherapy in high-risk premenopausal women with breast cancer who receive adjuvant chemotherapy. Danish breast cancer cooperative group 82b trial. N Engl J Med 1997, 337:949-955.

3. Overgaard M, Jensen MB, Overgaard J, Hansen PS, Rose C, Andersson M, Kamby C, Kjaer M, Gadeberg CC, Rasmussen BB, Blichert-Toft M, Mouridsen HT: Postoperative radiotherapy in high-risk postmenopausal breast-cancer patients given adjuvant tamoxifen. Danish breast cancer cooperative group DBCG 82c randomised trial. Lancet 1999, 353:1641-1648.

4. Joseph R, Jackson SM, Nhu L, Plenderleith IH, Spinelli JJ, Basco VE, Wilson KS, Knowling MA, Christopher ML C, Marilyn P, Coldman AJ, Olivotto IA: Adjuvant radiotherapy and chemotherapy in node-positive premenopausal women with breast cancer. NEMM 1997, 337:956-962.

5. Joseph R, Olivotto IA, Spinelli JJ, Norman P, Jackson SM, Wilson KS, Knowling MA, Coppin CML, Lorna W, Karen G, Nhu L, Ralph D, Coldman AJ, Mohamed M: Locoregional radiation therapy in patients with high- risk breast cancer receiving adjuvant chemotherapy: 20 -year results of the British Columbia randomized trial. J Natl Cancer Inst 2005, 97(2):116-126.

6. Darby SC, Mc Gale P, Taylor CW, Peto R: Long term mortality from heart disease and lung cancer after radiotherapy for early breast cancer: prospective cohort study of about 300,000 women in US SEER cancer registries. Lancet Oncol 2005, 6:557-565.

7. Giordano SH, Kuo YF, Freeman JL, Buchholz TA, Hortobagyi GN, Goodwin JS: Risk of cardiac death after adjuvant radiotherapy for breast cancer. J Natl Cancer Inst 2005, 97:419-424.

8. Chen RC, Lin NU, Mehra G, Harris JR, Bellon JR: Internal mammary nodes in breast cancer: diagnosis and Implications for patient management-a systematic review. JCO 2008, 26(30):4981-4989.

9. Tsai RJ, Dennis LK, Lynch CF, Snetselaar LG, Zamba GKD, Carol S-C: The risk of developing Arm lymphedema among breast cancer survivors: a meta-analysis of treatment factors. Ann Surg Oncol 2009, 16(7):1959-1972.

10. Kissin MW, QuercidellaRovere G, Easton D, Westbury G: Risk of lymphoedema following the treatment of breast cancer. Br J Surg 1986, 73:580-584

11. McDonald S, Rubin P, Phillips TL, Marks LB: Injury to the lung from cancer therapy: clinical syndromes, measurable endpoints, and potential scoring systems. Int J Radiat Oncol Biol Phys 1995, 31:1187-1203.

12. Rubin P, Casseratt GW: Respiratory system. In Clinical Radiation Pathology. Philadelphia: WB Saunders; 1968:423.

13. Trott KR, Herrmann T, Kasper M: Target cells in radiation pneumopathy. Int. J. Radiation Oncology Biol. Phys. 2004, 58(2):463-469.

14. Osterreicher J, Pejchal J, Skopek J, Mokry J, Vilasova Z, Psutka J, Vavrova J, Mazurova Y: Role of type II pneumocytes in pathogenesis of radiation pneumonitis: dose response of radiation-induced lung changes in the transient high vascular permeability period. Exp Toxicol Pathol 2004, 56(3):181-187.

15. Smith BD, Pan IW, Shih $Y C$, Smith GL, Harris JR, Punglia R, Pierce LJ, Jagsi $R$, Hayman JA, Giordano SH, Buchholz TA: Adoption of intensity-modulated radiation therapy for breast cancer in the United States. JNCl J Natl Cancer Inst 2011, 103(10):798-809.

16. Wennberg B, Gagliardi G, Sundbom L, Svane G, Lind P: Early response of lung in breast cancer irradiation radiologic density changes measured by $\mathrm{CT}$ and symptomatic radiation pneumonitis. Int I Radiat Oncol Biol Phys 2002, 52(5):1196-1206.

17. Pehr ARM L, Berit W, Giovanna G, Tommy F: Pulmonary complications following different radiotherapy techniques for breast cancer, and the 
association to irradiated lung volume and dose. Breast Cancer Res Treat 2001, 68:199-210.

18. Jarvenpaa R, Holli K, Pitkanen M, Hyodynmaa S, Rajala J, Lahtela SL, Ojala A Radiological pulmonary findings after breast cancer irradiation: a prospective study. Acta Oncol 2006, 45:16-22

19. Holli K, Pitkanen M, Jarvenpaa R, Rajala J, Lahtela S, Hyodynmaa S, Ojala A: Early skin and lung reactions in breast cancer patients after radiotherapy: prospective study. Radiother Oncol 2002, 64:163-169.

20. Lind PA, Marks LB, Hardenbergh PH, Clough R, Fan M, Hollis D, Hernando ML, Lucas D, Piepgrass A, Prosnitz LR: Technical factors associated with radiation pneumonitis after local +/- regional radiation therapy for breast cancer. Int. J. Radiation Oncology Biol. Phys. 2002, 52(1):137-143.

21. Nishioka A, Ogawa Y, Hamada N, Terashima M, Inomata T, Yoshida S: Analysis of radiation pneumonitis and radiation-induced lung fibrosis in breast cancer patients after breast conservation treatment. Oncol Rep 1999, 6:513-517.

22. Ulla Blom G, Berit W, Gunilla S, Hakan B, Pehr L: Reduction of radiation pneumonitis by V20-constraints in breast cancer. Radiat Oncol 2010, 5:99.

23. Krengli M, Sacco M, Loi G, Masini L, Ferrante D, Gambaro G, Ronco M, Magnani C, Carriero A: Pulmonary changes after radiotherapy for conservative treatment of breast cancer: a prospective study. Int. J. Radiation Oncology Biol. Phys. 2008, 70(5):1460-1467.

24. Akiko K, Kyosuke O, Takashi K, Shunsuke F, Hitoshi I, Hiromu N: Risk factors for radiation pneumonitis caused by whole breast irradiation following breast-conserving surgery. J Med Invest 2009, 56(3-4):99-110.

25. Rodrigues G, Lock M, D'Souza D, Edward Y, Van Dyk J: Prediction of radiation pneumonitis by dose-volume histogram parameters in lung cancer-a systematic review. Radiother Oncol 2004, 71:127-138.

26. Lind PA, Wennberg B, Gagliardi G, Rosfors S, Blom-Goldman U, Lidestahl A, Svane G: ROC curves and evaluation of radiation-induced pulmonary toxicity in breast cancer. Int. J. Radiation Oncology Biol. Phys. 2006, 64(3):765-770

27. Kwa SL, Lebesque JV, Theuws JC, Marks LB, Munley MT, Bentel G, Oetzel D, Spahn U, Graham MV, Drzymala RE, Purdy JA, Lichter AS, Martel MK, Ten Haken RK: Radiation pneumonitis as a function of mean lung dose: an analysis of pooled data of 540 patients. Int. J. Radiation Oncology Biol. Phys. $1998,42(1): 1-9$.

28. Rancati T, Ceresoli GL, Gagliardi G, Schipani S, Cattaneo GM: Factors predicting radiation pneumonitis in lung cancer patients: a retrospective study. Radiother Oncol 2003, 67:275.

29. Hernando ML, Marks LB, Bentel GC, Zhou SM, Hollis D, Das SK, Fan M, Munley MT, Shafman TD, Anscher MS, Lind PA: Radiation induced pulmonary toxicity: a dose-volume histogram analysis in 201 patients with lung cancer. Int J Radiat Oncol Biol Phys 2001, 51:650-659.

30. Oetzel D, Schraube P, Hensley F, Sroka-Pérez G, Menke M, Flentje M: Estimation of pneumonitis risk in three-dimensional treatment planning using dose-volume histogram analysis. Int J Radiat Oncol Biol Phys 1995, 33:455-460.

31. Kahan Z, Csenki M, Varga Z, Szil E, Cserhati A, Balogh A, Gyulai Z, Mandi Y, Boda $K$, Thurzo $L$ : The risk of early and late lung sequelae after conformal radiotherapy in breast cancer patients. Int. J. Radiation Oncology Biol. Phys. 2007, 68(3):673-681.

32. Bentzen SM, Skoczylas JZ, Marie O, Jens O: Radiotherapy-related lung fibrosis enhanced by tamoxifen. J Natl Cancer Inst 1996, 88(13):918-922.

33. Dorr W, Bertmann S, Herrmann T: Radiation induced lung reactions in breast cancer therapy : modulating factors and consequential effects. Strahlentherapie und Onkologie. Strahlenther Onkol. 2005, 181(9):567-573.

34. Taghian AG, Assaad SI, Niemierko A, Kuter I, Younger J, Schoenthaler R, Roche M, Powell SN: Risk of pneumonitis in breast cancer patients treated with radiation therapy and combination chemotherapy with paclitaxel. J Natl Cancer Inst 2001, 93(23):1806-1811.

35. McCurdy M, McAleer MF, Wei W, Ezhil M, Johnson V, Khan M, Baker J, Luo D, Ajani J, Guerrero T: Induction and concurrent taxanes enhance both the pulmonary metabolic radiation response and the radiation pneumonitis response in patients with esophagus cancer. Int J Radiat Oncol Biol Phys 2010, 76(3):816-823.

36. Robnett TJ, Machtay M, Vines EF, McKenna MG, Algazy KM, McKenna WG: Factors predicting severe radiation pneumonitis in patients receiving definitive chemoradiation for lung cancer. Int J Radiat Oncol Biol Phys 2000, 48:89.

37. Monson JM, Stark P, Reilly JJ, Sugarbaker DJ, Strauss GM, Swanson SJ, Decamp MM, Mentzer SJ, Baldini EH: Clinical radiation pneumonitis and radiographic changes after thoracic radiation therapy for lung carcinoma. Cancer 1998, 82:842.

38. Bjermer L, Franzen L, Littbrand B, Nilsson K, Angstrm T, Henriksson R: Effects of smoking and irradiated volume on inflammatory response in the lung of irradiated breast cancer patients evaluated with bronchoalveolar lavage. Cancer Res 1990, 50:2027-2030.

39. Johansson S, Bjermer L, Franzen L, Henriksson R: Effects of ongoing smoking on the development of radiation-induced pneumonitis in breast cancer and oesophagus cancer patients. Radiother Oncol 1998, 49:41-47.

40. Dang J, Li G, Xiaobe L, Yao L, Zhang S, Zhan Y: Analysis of related factors associated with radiation pneumonitis in patients with locally advanced non-small-cell lung cancer treated with three-dimensional conformal radiotherapy. J Cancer Res Clin Oncol 2010, 136:1169-1178.

41. Arpin D, Mahé MA, Servois V, Claude L: Predictive factors for acute radiation pneumonitis. Rev Pneumol Clin 2009, 65(3):177-186. Epub 2009 Jun 3.

42. Koga K, Kusumoto S, Watanabe K, Nishikawa K, Harada K, Ebibara H: Age factor relevant to the development of radiation pneumonitis in radiotherapy of lung cancer. Int J Radiat Oncol. Biol Phys 1988, 14:367-71.

43. Lind PARM, Bylund $H$, Wennberg B, Svensson C, Svane G: Abnormalities on chest radiographs following radiation therapy for breast cancer. Eur Radiol 2000, 10(3):484-489.

44. Javier J, Gonzalo V, Enrique A, Antonio L, Rafael G, Almansa JF: Changes in pulmonary function after incidental lung irradiation for breast cancer: a prospective study. Int. J. Radiation Oncology Biol. Phys. 2006, 65(5):1381-1388

45. Niemierko A, Goitein M: Modeling of normal tissue response to radiation: the critical volume model. Int J Radiat Oncol Biol Phys 1993, 25(1):135-145.

46. Rancati T, Wennberg B, Lind P, Svane G, Gagliardi G: Early clinical and radiological pulmonary complications following breast cancer radiation therapy: NTCP fit with four different models. Radiother Oncol 2007, 82:308-316.

47. Amy Yuen Meei T, Park EJH, Liang S, Chung HT: Three-dimensional volumetric analysis of irradiated lung with adjuvant breast irradiation. Int. J. Radiation Oncology Biol. Phys. 2009, 75(5):1309-1315.

48. Das IJ, Cheng EC, Gary F, Barbara F: Lung and heart dose volume analyses with CT simulator in radiation treatment of breast cancer. Int J Radiat Oncol Biol Phys 1998, 42(1):11-19.

49. Matzinger $\mathrm{O}$, Heimsoth I, Poortmans $\mathrm{P}$, Collette L, Struikmans $\mathrm{H}$, Van Den Bogaert W, Fourquet A, Bartelink H, Ataman F, Gulyban A, Pierart M, Van Tienhoven G: Toxicity at three years with and without irradiation of the internal mammary and medial supraclavicular lymph node chain in stage I to III breast cancer (EORTC trial 22922/10925). Acta Oncol 2010, 49:24-34.

50. Heuts EM, van der Ent FWC, von Meyenfeldt MF, Voogd AC: Internal mammary lymph drainage and sentinel node biopsy in breast cancer - a study on 1008 patients. Eur J Surg Oncol 2009, 35(3):252-257.

51. Farrus B, Vidal-Sicart S, Velasco M, Zanon G, Fernandez PL, Munoz M, Santamaria G, Albanell J, Biete A: Incidence of internal mammary node metastases after a sentinel lymph node technique in breast cancer and its implication in the radiotherapy plan. Int J Radiat Oncol Biol Phys 2004, 60:715-721.

52. Huang O, Wang L, Shen K, Lin H, Hu Z, Liu G, Wu J, Lu J, Shao Z, Han Q, Shen Z: Breast cancer subpopulation with high risk of internal mammary lymph nodes metastasis: analysis of 2,269 Chinese breast cancer patients treated with extended radical mastectomy. Breast Cancer Res Treat 2008, 107:379-387.

53. Ahn PH, Vu HT, Lannin D, Obedian E, DiGiovanna MP, Burtness B, Haffty BG: Sequence of radiotherapy with tamoxifen in conservatively managed breast cancer does not affect local relapse rates. J Clin Oncol 2005, 23(1):17-23.

54. Pierce $\sqcup$, Hutchins LF, Green SR, Lew DL, Gralow JR, Livingston RB, Osborne CK, Albain KS: Sequencing of tamoxifen and radiotherapy after breast-conserving surgery in early-stage breast cancer. J Clin Oncol 2005, 23(1):24-29.

55. Harris EE, Christensen VJ, Hwang WT, Fox K, Solin LJ: Impact of concurrent versus sequential tamoxifen with radiation therapy in early-stage breast cancer patients undergoing breast conservation treatment. J Clin Oncol 2005, 23(1):11-16.

56. Urbanic JJ, Lally B, Blackstock AW: The best-laid plans ... often go awry ... J Thorac Oncol 2009, 4:783.

57. Taghian AG, Assaad SI, Niemierko A, Kuter I, Younger J, Schoenthaler R, Roche M, Powell SN: Risk of pneumonitis in breast cancer patients 
treated with radiation therapy and combination chemotherapy with paclitaxel. J Natl Cancer Inst 2001, 93:1806.

58. Sharad G, Rao MS, Atif K, Lien H, Camille G, Haffty BG: Evaluation of acute locoregional toxicity in patients with breast cancer treated with adjuvant radiotherapy in combination with Bevacizumab. Int. J. Radiation Oncology Biol. Phys. 2011, 79(2):408-413.

59. Nagata S, Ueda N, Yoshida Y, Matsuda H, Maehara Y: Severe interstitial pneumonitis associated with the administration of taxanes. I Infect Chemother 2010, 16(5):340-344

60. Hamada K, Nagai S, Kitaichi M, Jin G, Shigematsu M, Nagao T, Sato A, Mishima M: Cyclophosphamide-induced late-onset lung disease. Intern Med 2003, 42(1):82-87.

61. Ogo E, Komaki R, Fujimoto K, Uchida M, Abe T, Nakamura K, Mitsumori M, Sekiguchi K, Kaneyasu Y, Hayabuchi N: A survey of radiation-induced bronchiolitis obliterans organizing pneumonia syndrome after breastconserving therapy in Japan. Int J Radiat Oncol Biol Phys 2008, 71(1):123-131. Epub 2007 Dec 3.

62. Zhao L, Wang L, Ji W, Wang X, Zhu X, Hayman JA, Kalemkerian GP, Yang W, Brenner D, Lawrence TS, Kong FM: Elevation of plasma TGF-beta1 during radiation therapy predicts radiation-induced lung toxicity in patients with non-small-cell lung cancer: a combined analysis from Beijing and Michigan. Int J Radiat Oncol Biol Phys 2009, 74(5):1385-1390. Epub 2009 Feb 21.

63. Delanian S, Porcher R, Balla-Mekias S, Lefaix JL: Randomized, placebocontrolled trial of combined pentoxifylline and tocopherol for regression of superficial radiation-induced fibrosis. J Clin Oncol 2003, 21(13):2545-2550.

doi:10.1186/1748-717X-8-268

Cite this article as: Gokula et al:: Meta-analysis of incidence of early lung toxicity in 3-dimensional conformal irradiation of breast carcinomas. Radiation Oncology 2013 8:268.

\section{Submit your next manuscript to BioMed Central and take full advantage of:}

- Convenient online submission

- Thorough peer review

- No space constraints or color figure charges

- Immediate publication on acceptance

- Inclusion in PubMed, CAS, Scopus and Google Scholar

- Research which is freely available for redistribution 